\title{
Tetrastyryl-BODIPY-Based Dendritic Light Harvester and Estimation of Energy Transfer Efficiency
}

2012

Vol. 14, No. 14 3636-3639

\author{
Ziya Kostereli, ${ }^{\dagger}$ Tugba Ozdemir, ${ }^{\ddagger}$ Onur Buyukcakir, ${ }^{\ddagger}$ and Engin U. Akkaya ${ }^{\star, \dagger, \neq}$ \\ Department of Chemistry and UNAM-National Nanotechnology Research Center, \\ Bilkent University, 06800 Ankara, Turkey
}

eua@fen.bilkent.edu.tr

Received May 28, 2012

\section{ABSTRACT}

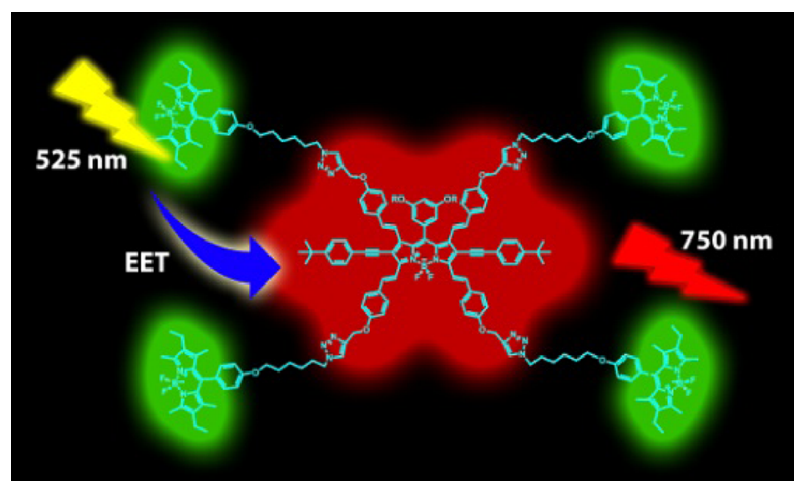

Versatile BODIPY dyes can be transformed into bright near-IR-emitting fluorophores by quadruple styryl substitutions. When clickable functionalities on the styryl moieties are inserted, an efficient synthesis of a light harvester is possible. In addition, clear spectral evidence is presented showing that, in dendritic light harvesters, calculations commonly based on quantum yield or emission lifetime changes of the donor are bound to yield large overestimations of energy transfer efficiency.

Efficient harvesting of solar radiation requires judiciously designed absorbers. Considering the fact that it would be difficult to have a single molecule with strong absorptions in the entire visible spectrum and near-IR (perfect black dye), it makes more sense to seek multichromophoric dye ensembles. Different chromophoric units can be brought together either by covalent bonds or by noncovalent interactions. In either case, excitation energy transfer (EET) from the donor chromophores (shorter wavelength absorption) to the acceptor (longer wavelength absorbing core) module is expected. The efficiency of energy transfer from the antenna chromophores to the central core is very important. In such multichromophoric light harvesters, energy transfer can be either through-space ${ }^{1}$ or through-bond. ${ }^{2}$ Through-space energy transfer is also possible between two or more free

\footnotetext{
'Department of Chemistry.

*UNAM-Institute of Materials Science and Nanotechnology.

(1) Förster, T. Z. Naturforsch. 1949, 4, 321-327.

(2) Dexter, D. L. J. Chem. Phys. 1953, 21, 836-850.
}

chromophoric units. This kind of energy transfer has been thoroughly studied, and in fact, the Förster (throughspace) energy transfer model is built on the interaction of such transition dipole coupled chromophoric pairs. Three important parameters determine the efficiency of energy transfer: donor-acceptor distance, relative orientations of the transition dipoles, and the spectral overlap between the relevant absorption and emission bands. In proteins, either utilizing endogenous fluorescence of tryptophan or using fluorescent labels, EET efficiency calculations based on quantum yield or lifetime changes have been successful, but proteins are large and flexible enough for orientation of the dipoles to be averaged, and typically, reference fluorophores are in the same microenvironment. This simplified energy transfer calculation approach was later carried out on covalently linked multichromophoric light harvesters. In these energy transfer cassettes, energy funnels, or dendritic light harvesters, energy transfer efficiency is calculated assuming that the original bimolecular model can be directly related to an energy transfer process in a 
covalently linked multichromophoric system with short separation between the chromophores and many flexible linkers and/or side chains compared to simple reference chromophore modules. It has been recognized for some time that these values for energy transfer efficiency represent an upper limit and in most cases a significant overestimation.

We have been interested in the synthesis and characterization of light-harvesting systems for some time. ${ }^{3}$ In many other examples, BODIPY chromophores have been utilized as either energy donors or energy acceptors. In recent years, brightly emitting BODIPY dyes are in the focus of renewed interest with an eye toward practical applications and new derivatization opportunities. ${ }^{4}$ One particular derivatization which already proved to be highly fruitful is Knoevenagel condensation of acidic methyl groups found in methyl-substituted BODIPYs with selected aromatic aldehydes. Mono- and distyryl-BODIPY compounds were reported in $2001^{5}$ and $2006,{ }^{6}$ respectively, and in 2009, our research group reported ${ }^{7}$ both tri- and tetrastyryl-BODIPY derivatives. Each styryl unit increases $\pi$-conjugation further, shifting the main absorption band $\left(\mathrm{S}_{0} \rightarrow \mathrm{S}_{1}\right.$ transition) to lower energy (longer wavelength region). By these simple sequences of reactions, the absorption band of BODIPY dyes can be easily tuned in the range of 500-900 nm. Relative ease of this modification alone puts BODIPY derivatives in a very privileged place among organic chromophores.

In order to investigate light-harvesting properties of near-IR-emitting tetrastyryl BODIPY dyes, we targeted modular harvesters 4 and $\mathbf{5}$ (Figure 1). The synthesis plan makes use of common intermediate $\mathbf{3}$. Compound $\mathbf{3}$ is a tetrastyryl dye obtained by quadruple Knoevenagel condensation of a previously reported 2,6-disubstituted intermediate with 4-propynyloxybenzaldeyhde.

Key intermediate compound $\mathbf{3}$ carries four clickable terminal alkyne groups. This design conveniently allows

(3) (a) Coskun, A.; Akkaya, E. U. J. Am. Chem. Soc. 2006, 128, 14474-14475. (b) Bozdemir, O. A.; Cakmak, Y.; Sozmen, F.; Ozdemir, T.; Siemiarczuk, A.; Akkaya, E. U. Chem.-Eur. J. 2010, 16, 6346-6351. (c) Kolemen, S.; Bozdemir, O. A.; Cakmak, Y.; Barin, G.; Erten-Ela, S.; Marszalek, M.; Yum, J.-H.; Zakeeruddin, S. M.; Nazeeruddin, M. K.; Grätzel, M.; Akkaya, E. U. Chem. Sci. 2011, 2, 949-954. (d) Atilgan, S.; Ozdemir, T.; Akkaya, E. U. Org. Lett. 2010, 12, 4792-4795. (e) Bozdemir, O. A.; Yilmaz, M. D.; Buyukcakir, O.; Siemiarczuk, A.; Tutas, M.; Akkaya, E. U. New J. Chem. 2010, 34, 151-155. (f) Guliyev, R.; Coskun, A.; Akkaya, E. U. J. Am. Chem. Soc. 2009, 131, 9007-9013. (g) Barin, G.; Yilmaz, M. D.; Akkaya, E. U. Tetrahedron Lett. 2009, 50, 1738-1740. (h) Yilmaz, M. D.; Bozdemir, O. A.; Akkaya, E. U. Org. Lett. 2006, 8, 28712873. (i) Saki, N.; Dinc, T.; Akkaya, E. U. Tetrahedron 2006, 62, 27211740

(4) (a) Loudet, A.; Burgess, K. Chem. Rev. 2007, 107, 4891-4932. (b) Ulrich, G.; Ziessel, R.; Harriman, A. Angew. Chem., Int. Ed. 2008, 47, 1184-1201. (c) Burghart, A.; Thoresen, L. H.; Chen, J.; Burgess, K.; Bergstrom, F.; Johansson, L. B.-A. Chem. Commun. 2000, 2203-2204. (d) Wan, C.-W.; Burghart, A.; Chen, J.; Bergström, F.; Johansson, L. B.-A.; Wolford, M. F.; Kim, T. G.; Topp, M. R.; Hochstrasser, R. M.; Burgess, K. Chem.-Eur. J. 2003, 9, 4430-4441. (e) Ulrich, G.; Goze, C.; Guardigli, M.; Roda, A.; Ziessel, R. Angew. Chem., Int. Ed. 2005, 44, 3694-3698. (f) Harriman, A.; Mallon, L.; Ziessel, R. Chem-Eur. J. 2008, 14, 11461-11473.

(5) Coskun, A.; Akkaya, E. U. Tetrahedron Lett. 2004, 45, 49474949.

(6) Dost, Z.; Atilgan, S.; Akkaya, E. U. Tetrahedron 2006, 62, 8484 8488

(7) Buyukcakir, O.; Bozdemir, O. A.; Kolemen, S.; Erbas, S.; Akkaya, E. U. Org. Lett. 2009, 11, 4644-4647.<smiles>CCCCCCOc1ccc(C2=C3C(C)=C(CC)C(C)=[N+]3[P+](F)(F)n3c(C)c(CC)c(C)c32)cc1</smiles>

1
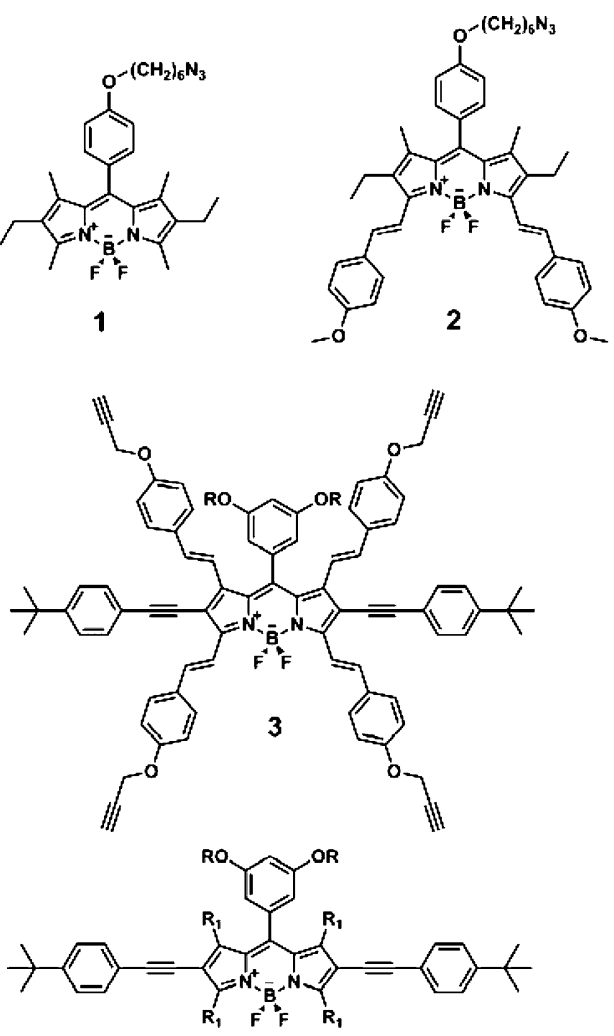

$R_{1}=$

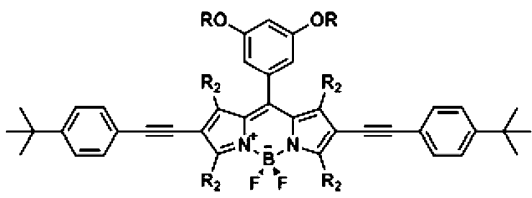

5

$\mathbf{R}_{2}=$

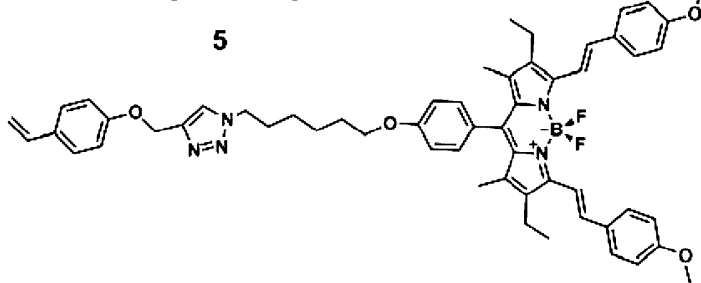

Figure 1. Structures of the modules used in the construction of tetrastyryl-BODIPY-based light harvester and the target compounds $\mathbf{4}$ and $\mathbf{5}$. R denotes decyl.

modular attachment of essentially any azide-functionalized chromophore. In the synthesis of compound $\mathbf{4}$, we reacted intermediates $\mathbf{3}$ and $\mathbf{1}$. For compound $\mathbf{5}$, modular units $\mathbf{2}$ and $\mathbf{3}$ were joined together by click chemistry.

Our light-harvesting design involves attachment of four shorter wavelength antenna units and one central core. Absorbance spectra of compound 1, 2, 3, 4, and 5 are shown in Figure S1 (Supporting Information). As expected, both light harvesters show two major absorption bands corresponding to two different chromophores. In compound 4, absorption bands with peaks at 545 and $730 \mathrm{~nm}$ 
Table 1. Energy Transfer Rate and Efficiencies of Dendritic Light Harvesters 4 and $\mathbf{5}$

\begin{tabular}{ccccc}
\hline compound $^{a}$ & $\lambda_{\text {ems }}(\mathrm{nm})$ & \multicolumn{1}{c}{$\tau(\mathrm{ns})^{b}$} & $k_{\text {en }}$ (Förster) $\left(\mathrm{s}^{-1}\right)$ efficiency (\%) \\
\hline $\mathbf{4}$ & 537 & $0.13(40 \%)$ & $1.97 \times 10^{9}$ & 90 \\
& & $4.84(60 \%)$ & & \\
$\mathbf{5}$ & 672 & $0.23(24 \%)$ & $2.05 \times 10^{9}$ & 92 \\
& & $4.10(76 \%)$ & & \\
$\mathbf{1}$ & 537 & 5.02 & & \\
$\mathbf{2}$ & 672 & 4.55 & & \\
$\mathbf{3}$ & 748 & 3.41 & &
\end{tabular}

${ }^{a}$ Data acquired in $\mathrm{CHCl}_{3}$ in dilute solutions. ${ }^{b}$ Data in parentheses refer to weight percentage of the contribution to emission decay.

are apparent, and in compound $\mathbf{5}$, the two bands are centered around 652 and $732 \mathrm{~nm}$. An experimental confirmation of energy transfer is readily obtained by comparing reference modules and the covalently assembled light harvesters. Figures S2 and S3 show such comparisons. Emission spectra at equal concentrations of compounds 1 and 4 reveal a significant quenching of shorter wavelength BODIPY emission in compound 4 . Similar quenching of shorter wavelength emission is apparent in compound $\mathbf{5}$, as well. This is no doubt an indicator of energy transfer efficiency. Another commonly employed demonstration of energy transfer is based on "enhanced core emission", ${ }^{8}$ which is essentially obtained by exciting longer wavelength-emitting modules at a common shorter wavelength used for exciting a light-harvesting system. As an example, $3 / 4$ and $3 / 5$ emissions excited at a shorter wavelength peak of $\mathbf{4}$ or $\mathbf{5}$, respectively, can be compared (Figures S2 and S3, Supporting Information). It is clear, but also not surprising, that emission from the core is stronger in light harvesters $\mathbf{4}$ and $\mathbf{5}$ compared to that of the core module 3 when excited at 525 and $655 \mathrm{~nm}$, respectively. Quantitative calculations of energy transfer can be based on the changes in lifetime or quantum yield. ${ }^{9}$

This is again valid, only if bimolecular energy transfer arguments can be easily carried to larger and flexible unimolecular dendritic light harvesters. Spectral data and energy transfer rate/efficiencies are presented at Table S1 and Table 1, respectively. In light harvesters $\mathbf{4}$ and $\mathbf{5}$, again, as expected, shorter wavelength absorption is stronger with larger extinction coefficients over 300 000. Emission decay profiles from compounds $\mathbf{4}$ and $\mathbf{5}$ are biexponential as expected since there is always residual emission from the shorter wavelength chromophores in addition to longer wavelength emission from the central core (Table 1). On the basis of the significantly reduced emission lifetimes of the donor moieties, we can calculate 90 and $92 \%$ energy transfer efficiency values for light harvesters $\mathbf{4}$ and $\mathbf{5}$, respectively.

Calculations based on quantum yields also result in comparable efficiency values. However, a simple inspection

(8) Yilmaz, M. D.; Bozdemir, O. A.; Akkaya, E. U. Org. Lett. 2006, 8 , 2871-2873.

(9) Valeur, B. Molecular Fluorescence, Principles and Applications; Wiley-VCH: Weinheim, Germany, 2002.

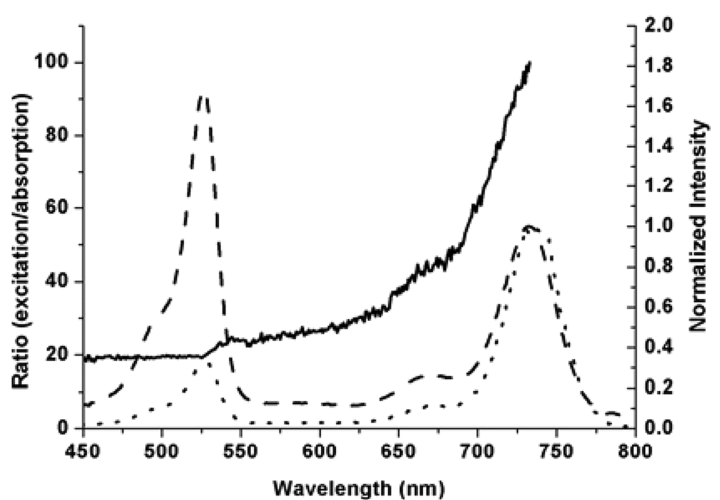

Figure 2. Percent energy transfer efficiency of $\mathbf{4}$ (solid line) as a function of wavelength of excitation. Excitation spectrum of $\mathbf{4}$ (dotted line) and absorption spectrum of $\mathbf{4}$ (dashed line), normalized at $735 \mathrm{~nm}$.

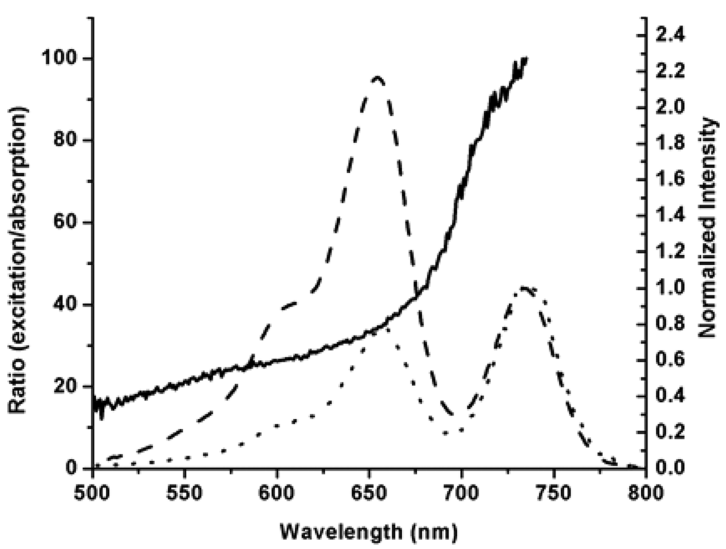

Figure 3. Percent energy transfer efficiency of 5 (solid line) as a function of wavelength of excitation. Excitation spectrum of $\mathbf{5}$ (dotted line) and absorption spectrum of 5 (dashed line), normalized at $735 \mathrm{~nm}$.

of excitation spectra suggests that these efficiency values are largely overestimated. Same methodology has been used in assessing energy transfer efficiencies in a large number of light-harvesting molecules, energy cascades, and energy transfer cassettes. ${ }^{3 e, 10}$ Recently, in a dendritic light harvester designed for solar concentration, we have experimentally demonstrated that, in such flexible lightharvesting ensembles, simple calculations based on lifetime changes are not applicable. ${ }^{11}$ Deviation between energy transfer efficiencies calculated by quantum yield/lifetime

(10) (a) Li, F.; Yang, S. I.; Ciringh, Y.; Seth, J.; Martin, C. H.; Singh, D. L.; Kim, D.; Birge, R. R.; Bocian, D. F.; Holten, D.; Lindsey, J. L. J. Am. Chem. Soc. 1998, 120, 10001-10017. (b) Ziessel, R.; Harriman, A. Chem. Commun. 2011, 47, 611-631. (c) Hawker, C. J.; Frechet, J. M. J. J. Chem. Soc., Chem. Commun. 1990, 1010-1013. (d) Hawker, C. J.; Frechet, J. M. J. J. Am. Chem. Soc. 1990, 112, 7638-7947. (e) Adronov, A.; Frechet, J. M. J. Chem. Commun. 2000, 1701-1710. (f) Dichtel, W. R.; Hecht, S.; Frechet, J. M. J. Org. Lett. 2005, 7, 4451-4454.

(11) Bozdemir, O. A.; Erbas-Cakmak, S.; Ekiz, O. O.; Dana, A.; Akkaya, E. U. Angew. Chem., Int. Ed. 2011, 50, 10907-10912. 
changes and calculations based on excitation spectra can be very large. This is due to disregarding any emergent quenching process in the covalent assembly and treating all nonradiative processes involving the donor as energy transfer. One simple way of presenting energy transfer efficiency as a function of wavelength was proposed by Wittmershaus in $1998 ;{ }^{12}$ it is a comparison of absorption and excitation spectra, normalized at the peak wavelength of absorption of the putative energy acceptor.

In this way, the ratio of excitation to absorption values yields a plot of energy transfer efficiency as a function of excitation wavelength. Figure 2 and Figure 3 show two such operations done for the light harvesters 4 and $\mathbf{5}$. From these ratios plotted as a function of wavelength, it is clear that in the region that corresponds to the absorption of the energy donor (antenna chromophores) energy transfer efficiency is actually closer to $20-30 \%$. This discrepancy, as mentioned previously, is due to the availability of additional vibrational and collisional nonradiative decay pathways in larger molecules incorporating a number of

(12) Roberts, D. V.; Wittmershaus, B. P.; Zhang, Y.-Z.; Swan, S.; Klinosky, M. P. J. Lumin. 1998, 79, 225-231. chromophores tethered with flexible linkers. A thorough understanding of energy transfer process in large multichromophoric systems is quite important, but before that is to be done, some persistent misunderstandings and mistakes in the literature have to be addressed and corrected. We are hoping that a clarification of the energy transfer efficiency issue will facilitate the design and synthesis of novel and unequivocally more efficient light harvesters and solar concentrators. We are also confident that tetrastyryl-BODIPY dyes or similarly tetra-functionalized BODIPY dyes will continue to be at the core of these improved light-harvesting assemblies. Our own work to that end is in progress.

Acknowledgment. This research was supported by National Boron Research Institute (BOREN-2011-Ç,0281).

Supporting Information Available. Methods, experimental procedures, additional spectral data. This material is available free of charge via the Internet at http:// pubs.acs.org.

The authors declare no competing financial interest. 